\title{
Varying cross-sectional volatility in the South African equity market and the implications for the management of fund managers
}

\author{
H. Raubenheimer \\ School of Management Studies, University of Cape Town, \\ Private Bag X3, Rondebosch 7701, and \\ University of Stellenbosch Business School, PO Box 610, Bellville 7535 \\ Republic of South Africa \\ heidiraub@telkomsa net
}

Received February 2010

\begin{abstract}
Modern portfolio theory is founded on an understanding of longitudinal volatility but it is the cross-sectional dispersion among investment returns that provide active portfolio managers with their competitive investment opportunities. The varying cross-sectional volatility in the South African equity market provides varying opportunity sets for active managers: the higher the cross-sectional volatility, the greater the opportunity for active risk taking, all other things being equal. This article argues that cross-sectional volatility must be considered hand-in-hand with risk limits and active risk targets when investment mandates are set and when mandated risk compliance is monitored.
\end{abstract}

*To whom all correspondence should be addressed.

\section{Introduction}

Sapra (2008), Ankrim and Ding (2002) and De Silva, Sapra and Thorley (2001), amongst others, point out that modern portfolio theory is founded on an understanding and an emphasis on time series or longitudinal volatility. Both Markowitz's groundbreaking 1952 introduction of a meanvariance paradigm and the Fundamental Law of Active Management ${ }^{1}$ " "Alpha is IC times volatility times score" require a time-series estimation of risk. This estimation usually involves successive periods of realised or forecast performance.

But when fund managers decide on how to allocate the finite pool of assets under their management among various investments, it is the cross-sectional dispersion of expected returns that is required in order to provide them with a reasonable opportunity for expressing relative preferences. As Sapra (2008) points out, if all securities had perfect correlations with each other, there would be no crosssectional dispersion in their returns and therefore no way for an active manager to achieve excess-of-benchmark performance or incur any active risk. Without crosssectional volatility, the active fund manager would be unable to deliver performance which was in any way distinct from their benchmark or any of their competitors.

Solnik and Roulet (2000) explored the nature of crosssectional correlation in the context of discerning the relationships between global markets as part of the global allocation decision. Traditionally, longitudinal or time-series data would be used to estimate correlation between the

\footnotetext{
${ }^{1}$ Grinold (1989) and Grinold (1994).
}

various global markets' performances. Typically, this would be done using a rolling 60 month window of simultaneous returns across world markets.

Solnik and Roulet (2000) point out that there are several problems with this type of measurement of global correlations. Firstly, the measurement of longitudinal relationships is unconditional i.e. it assumes that the relationships between global markets don't change over time and neither do the distributions of the returns of these markets. Furthermore, each subsequent estimate is highly dependent on the previous estimate and therefore also resistant to changes in the global market relationships. Although various weighted measures and autoregressive solutions exist for this problem, they either require a large number of estimations, a diagonal matrix or an ad hoc system of time-series weights which don't necessarily solve the dependence problem.

Solnik and Roulet (2000) propose that a cross-sectional, "instantaneous" measure of correlation is more appropriate and more capable of picking up on changing trends in market relationships. These authors find that the crosssectional method they proposed is more dynamic and that changes in this measure helped predict changes in the longitudinal estimation better than a time series approach would.

Changes in the volatility, either longitudinal or crosssectional, are of concern to investors and asset management selectors as they signal changes in the professional money management environment. Bernstein (1998) observed an apparent decreasing dispersion over time (from 1969 to 
1997) of fund returns in the US as well as the decreasing spread in the top performing portfolios relative to the benchmark. In this article, Bernstein puts forward two hypotheses: a) markets have become increasingly competitive and therefore it is increasingly difficult to significantly outperform the competition or b) risk management and the fear of being "wrong and alone" 2 has created convergent investments across portfolios without the concentration of risk required to produce star performance. Bernstein provides some tantalising but exploratory empirics into the latter and this hypothesis would provide a fascinating future research project into the behaviour of professional money managers. However, in this article it is the former hypothesis is that is of interest.

Bernstein (1998) uses baseball as an analogy of what happens to star performers when the variation in the performance of all athletes wanes. In 130 years of baseball data, the batting averages have hardly varied. However, the standard deviation around that long-term mean has diminished and reached a plateau. The consequence of this diminishing variation has been the disappearance of the ".400 star hitter". While new records continue to be set in individual sports, stars within team sports can disappear as a consequence of improved defence and competitive strategies.

Bernstein (1998) likened this to the field of professional investment management where he mused that the US stock market may have become increasingly efficient. Bernstein went so far as to show the waning of the spread in Warren Buffet's portfolios' performance (the investment management equivalent of a star athlete!) relative to the S\&P 500 up to this 1998 article. Bernstein argues that even a skilled, star investor such as Buffet, with no regard for benchmarks, has found his portfolio's performance spread relative to the $S \& P 500$ decreasing over time.

However, subsequent to 1997, Ankrim and Ding (2002) observed an increase in market volatility and noticed that the cross-sectional volatility of the market was also increasing. Ankrim and Ding (2002) makes the connection between longitudinal or time-series volatility and cross-sectional volatility, deriving a mathematical link between overall market volatility, sector volatility and intra-sector, crosssectional volatility. (Their results hold whether sectors are considered or not.)

The authors, mindful of the thinking of the time (2001) that equity market volatility was on the increase, questioned the fact that active portfolio returns were increasing in their dispersion in the same way and suggest that both are a function of increasing cross-sectional volatility, which is, after all, the environment in which an active manager is active.

Ankrim and Ding (2002) postulates a number of possible reasons for the observed increase in cross-sectional volatility at the time, namely: the trend towards smaller, more focussed companies; companies listing their equity earlier in

\footnotetext{
${ }^{2}$ A phrase coined by Mark Kritzman in his 1998 article, "Wrong and Alone".
}

the company's life cycle than has been the case historically, the influence of day-traders, less expensive trading and greater financial innovation, increases in financial leverage and shocks to the discount rates applied to company valuations. Certainly, the South African and other emerging/developing markets are subject to similar trends and practices and the effects may well be seen in our changing equity volatility.

De Silva et al. (2001) observed the highest recorded crosssectional volatility in the US in 1999 (increasing from the last quarter of 1998 to 2000). In this article, the authors speculate as to the reason for this unprecedented dispersion, which they say economic historians would suggest is attributable to fundamental changes in the competitive advantages among companies. The authors suggest a new factor in security returns such as the impact of technology or alternatively a purely idiosyncratic event as possible culprits. The focus of De Silva et al. (2001) is to remedy the view of ex post performance in the light of varying crosssectional dispersion.

Ten years before the De Silva et al. (2001) article, Sharpe (1991) addressed the basic arithmetic of ex post portfolio performance measurement without any market efficiency assumptions or statistical simplifications required. Sharpe (1991) points out that when we consider the performance of various managers at any point in time in an equally weighted manner in order to assess their relative success, we incur various biases and mathematical violations.

Firstly, Sharpe (1991) makes the point that the average actively managed dollar (i.e. capitalisation weighted) cannot, before costs, deliver performance different to the average passively managed dollar. It follows that, after costs, capitalisation weighted investment dollars must underperform passive dollars when actively managed. Although mathematically obvious, Sharpe points out several performance monitoring practices that violate these basic tenets.

Firstly, when active portfolios which are compelled to hold cash are compared to equity-only benchmarks, the average dollar so invested will underperform the benchmark in good times and over perform in bad times. Another classic case of inappropriate averaging is when only surviving portfolios are used as a performance comparison. Survivorship bias omits the dollars that were transferred to another investment portfolio during the performance period in question.

Sharpe also points out the potential for a small-cap bias when equally-weighted manager averages are compared to the market as a whole. If portfolios of smaller fund sizes show a preference to smaller capitalisation stocks as is typical, the "average" portfolio will overweight smaller portfolios, thereby overweighting small caps in the "average" performance.

Small-cap bias is one of the reasons that capitalisation peer group comparisons are ill-advised. The most compelling argument against peer benchmarks are that, since capitalisation-weighted active portfolios will, by virtue of pure mathematics, underperform passive portfolios after 
costs, a peer group benchmark is necessarily an underperforming benchmark relative to a passive capitalisation-weighted index.

De Silva et al. (2001) extends the Sharpe (1991) argument regarding fund returns and their relationship to stock returns by showing that the value-weighted cross sectional dispersion of security returns must necessarily be related to the value-weighted cross section dispersion of active portfolio returns. Although diversification within portfolios would necessarily mean that portfolio returns are less dispersed than security returns, the relationship between the cross-sectional variations in each would hold.

De Silva et al. (2001) derives a mathematical relationship between security return dispersion, market return and idiosyncratic risk (refer Equation 1) to inform the expectation of dispersion among securities. Relying on some simplifications, specifically an equally-weighted market portfolio and a common distribution of idiosyncratic risk across stocks at any given time ${ }^{3}$, this derivation shows that expected cross sectional dispersion increases with a) increasing dispersion among stock betas, increasing idiosyncratic risk across stocks and market performance that differs increasingly from the risk free rate (either positively or negatively).

Equation 1: Relationship between market dispersion and security dispersion

$E\left(D_{t}^{2}\right)=\sigma_{\beta, t}^{2}\left(R_{M, t}-r_{f, t}\right)^{2}+\sigma_{\varepsilon, t}^{2}$

where

$E\left(D_{t}^{2}\right)$ is the expected (equal-weighted) cross-sectional dispersion among securities over an investment period, $t$,

$\sigma_{\beta, \mathrm{t}}^{2}$ is the cross-sectional variance of stock betas around one over this same period,

$\mathrm{R}_{\mathrm{M}, \mathrm{t}}-\mathrm{r}_{\mathrm{f}, \mathrm{t}}$ is the excess-of-risk-free rate return of the (equalweighted) market over the investment period, $t$ and

$\sigma_{\varepsilon, \mathrm{t}}^{2}$ is the idiosyncratic risk which is the same for all stocks over this period.

De Silva et al. (2001) extends this derivation to illustrate the relationship between portfolio performance dispersion and overall market performance (refer Equation 2). It follows that, since both portfolio and security dispersion are related to idiosyncratic risk, portfolio and security dispersion must also be related to each other.

Equation 2: Relationship between portfolio dispersion and security dispersion

$E\left(D_{p}^{2}\right)=\sigma_{\beta_{p}}^{2}\left(R_{M}-r_{f}\right)^{2}+\sigma_{\varepsilon_{p}}^{2}$

where

\footnotetext{
${ }^{3}$ The derivation has the CAPM segmentation of return as its starting point. Without a common distribution of idiosyncratic return from which to draw each stock's idiosyncratic return, the cross-sectional distribution of stock returns would be complex and non-normal.
}

$E\left(D_{p}^{2}\right)$ is the expected (equal-weighted) cross-sectional dispersion among portfolios of securities,

$\sigma_{\beta_{p}}^{2}$ is the cross-sectional variance of portfolio betas (which, if stocks are selected randomly will be $\left.\frac{\sigma_{\beta, \mathrm{t}}^{2}}{\mathrm{~N}}\right)$ and

$\sigma_{\varepsilon}^{2}$ is the idiosyncratic risk of portfolios of securities (which, under the assumption of zero correlation among idiosyncratic security returns is equal to $\frac{\sigma_{\varepsilon}^{2}}{\mathrm{~N}}$ where $\mathrm{N}$ is the number of stocks randomly selected in the portfolio.

Empirically, in their 2001 study, the authors find a coefficient of determination (R-squared) of $91 \%$ between the annual dispersion in the value weighted active portfolio performances in US equity mutual funds ${ }^{4}$ and the weighted cross-sectional volatility of securities on the US market from 1981 to 2000 . They conclude that there must therefore be very little that changes in market efficiency, manager talent or changing trends in asset management (such as a trend towards specialised portfolios or concentrated portfolios etc) can be contributing to the dispersion in portfolio manager performances. Furthermore, the article finds no evidence of a time trend in the relationship between market dispersion and portfolio dispersion in the US.

$\mathrm{Yu}$ and Sharaiha (2007) develop the findings of De Silva et al. (2001) by looking at cross-sectional dispersion as it informs the ex ante risk budgeting decision. The authors argue that, in an active management context, active positions must be taken in a portfolio in such a way that the extent of the position is justified by the size and reliability of the expected "alpha". As such, Yu and Sharaiha (2007) presents cross-sectional volatility as a method for measuring active management opportunities and what the authors term the "alpha-granularity" of markets at any point in time.

In an attempt to address the risk-budgeting decision with regards to top-down and bottom-up allocation, $\mathrm{Yu}$ and Sharaiha (2007) introduces the orthogonal relationship between asset allocation dispersion and stock-selection dispersion, collectively constituting the total return dispersion at any given time. This method enables a comparison between these two components of the risk budgeting decision within the common basis of the alphaopportunities available at the time.

The authors go on to recommend that such an analysis be compared to the existing dispersion in the active weights of a portfolio to assess whether the alpha-risk budget is being invested with similar ratios. A ranked correlation between the dispersion within sectors for a portfolio versus the dispersion within sectors for a benchmark gives an indication of the closeness of the risk budgeting decision with the alpha opportunities in the market, although portfolios should be constructed in anticipation of future alpha opportunities.

\footnotetext{
${ }^{4}$ The authors use the Morningstar database.
} 
In Yu and Sharaiha (2007), the authors show by derivation that the un-weighted cross-sectional dispersion is directly proportional to the returns on a dollar-neutral ${ }^{5}$ investment. In this way, the authors propose the use of cross-sectional volatility in a hedge fund context as a perfect hindsight performance benchmark. They propose that, when assessing the skill of the portfolio manager to allocate their risk budget, the dispersion of the funds' returns be compared to the realised dispersion of the appropriate investment universe: the higher the correlation between the two, the more appropriate the risk budgeting has been.

Finally, Yu and Sharaiha (2007) derive the mathematical relationship showing that the expected (weighted) crosssectional volatility is equal to a) the differential between the weighted average stock volatility and market volatility and b) the dispersion among expected stock returns. The authors continue, using a multivariate diffusion approach as return generating processes, and derive a similar relationship to that of Sapra (2008) (refer Equation 3): cross-sectional volatility (unweighted) is proportional to the average stock return volatility times 1 minus the average correlation among stocks.

Yu and Sharaiha (2007) goes so far as to argue that falling dispersion (decreasing $\sigma_{\mathrm{cs}}^{2}$ ) is a business risk to active managers, particularly managers of long/short portfolios. As such, one of the article's suggested remedies for the active portfolio management business is to hedge their revenue against falling cross-sectional volatility by employing the use of variance swaps and/or dispersion trades.

Equation 3: The relationship between cross-sectional volatility, average volatility and average correlation

$\sigma_{\mathrm{cs}}^{2} \propto \overline{\sigma_{1}^{2}}(1-\bar{\rho})$

where

$\sigma_{\mathrm{cs}}^{2}$ is the expected weighted cross-sectional volatility,

$\overline{\sigma_{1}^{2}}$ is the average security volatility (longitudinal) and

$\bar{\rho}$ is the average correlation between pairs of securities.

Extending the work of De Silva et al. (2001), Sapra (2008) looks at the loss of efficiency caused by unexpected (i.e. incorrectly forecast) changes in cross-sectional dispersion. In this article, an expression relating the estimation error in cross-sectional volatility to the realised active risk is derived as follows:
Equation 4: The relationship between unexpected change in cross-sectional volatility and realised active risk.

$\frac{\sigma_{\mathrm{A}}}{\widehat{\sigma_{\mathrm{A}}}}=\frac{\sigma_{\mathrm{cs}}}{\widehat{\sigma_{\mathrm{cs}}}}$

where

$\sigma_{\mathrm{cs}}$ and $\widehat{\sigma_{\mathrm{cs}}}$ are the realised and forecast cross-sectional standard deviation of the investment universe respectively and,

$\sigma_{\mathrm{A}}$ and $\widehat{\sigma_{\mathrm{A}}}$ are the realised and target active risk of a portfolio.

Sapra (2008) shows that this "shock" to cross sectional risk implies a decrease in the information ratio of a manager's realised performance - a ratio which is used as indicator of manager skill to potential investors and existing clients.

In Gorman, Sapra and Weigand (2009), the findings of Sapra (2008) are extended with an investigation into the predictability of cross-sectional volatility using, in particular, the VIX ${ }^{6}$ (implied volatility index). Other authors such as Ratner, Meric and Meric (2006), Clarke, De Silva and Thorley (2010) and Ang, Xing and Zhang (2006) have attempted to use cross-sectional dispersion as a predictor of stock level performance and volatility. In this article, the focus is on the implications of varying cross-sectional dispersion for the mandate setting and monitoring process rather than forecasting volatility or returns.

This article begins the analytical section with an empirical and historical analysis of the changes in cross-sectional volatility in the South African equity market showing the extent to which cross-sectional variation changes over time. The next section explores the impact of varying crosssectional dispersion on mandate and fund objective setting, particularly the effect on actively managed funds when active risk expectations are held constant. Furthermore, this section looks at the ongoing monitoring and management of active funds' mandate compliance with respect to active risk as a result of changes in cross-sectional dispersion of securities.

\section{Historical cross-sectional dispersion on the JSE}

Following the methodology of Ankrim and Ding (2002), the weighted cross-sectional volatility for any investment period is defined and calculated as follows:

Equation 5: Realised cross sectional variance

$\mathrm{s}_{\mathrm{cs}, \mathrm{t}}^{2}=\sum_{\mathrm{i}}^{\mathrm{N}} \mathrm{w}_{\mathrm{i}, \mathrm{t}-1}\left(\mathrm{R}_{\mathrm{i}, \mathrm{t}}-\mathrm{R}_{\mathrm{m}, \mathrm{t}}\right)^{2}$

where:

\footnotetext{
${ }^{6}$ The South African equivalent is the SAVI.

${ }^{5}$ Equal quantities of long and short investments with a net value of zero. 
$\mathrm{s}_{\mathrm{cs}, \mathrm{t}}^{2}$ is the weighted realised cross-sectional $(c s)$ variation of a particular benchmark or index over a particular investment period,

$\mathrm{w}_{\mathrm{i}, \mathrm{t}-1}$ is the weight (typically market capitalisation) of each stock, i, at time, $t-1$, in the benchmark/index of concern,

$R_{i, t}$ is the total return ${ }^{7}$ for each stock, $i$, from time $t-1$ to time $t$, one month later

$\mathrm{R}_{\mathrm{m}, \mathrm{t}}$ is the corresponding benchmark/index return or the weighted average return across stocks over the same month.

\section{FTSE/JSE All Share Index}

Figure 1 depicts the weighted monthly ${ }^{8}$ cross-sectional standard deviation (the square root of Equation 5) over time of the FTSE JSE All Share Index or "J203" (the bold line is a 6-month moving average of the same). Note the extent of the change in cross-sectional standard deviation over time: from low levels in the late-90's ${ }^{9}$, increasing in just over three years to peak in the recovery just after the 1998 market crash (the maximum to date of $21 \%$ occurred in October 1998). The slow decline in cross-sectional volatility from 1998 seemed to have hit its lowest point in our market between 2004 and 2006 (the minimum to date of $4 \%$ occurred in July 2004) and increased fairly sharply since. Although the history presented here is shorter than that presented by Bernstein (1998) and De Silva et al. (2001), we see similarly low levels of dispersion on the JSE in the mid to late 1990's picking up at a similar time to the US evidence presented in De Silva et al. (2001). However, 1999 and 2000 saw unprecedented high levels of cross-sectional dispersion in the US where, in South Africa, ours had already declined substantially. In evidence presented by Sapra (2008), over the time of the 2008 financial crisis, he showed that the US market appeared to be returning to these high levels again in much the same way the South African market has in 2008. The most recent year has seen what appears to be a very rapid decline in cross-sectional dispersion of opportunities on the JSE.

\footnotetext{
${ }^{7}$ The total return was calculated by including all dividends (including scrip) on the applicable ex-dividend date into the return calculation. Total return therefore represents both capital gain (growth in the share price) and dividend yield.

${ }^{8}$ It's typical in a portfolio management context to use monthly performance statistics as a high frequency performance monitoring tool towards quarterly and annual performance reports to the client. It is not common practice to report on fund performance at a higher frequency.

${ }^{9}$ Although J203 index data is available from an earlier date, the number of constituents in the index halved from 319 in December 1996 to 155 in January 1997 as a result of changes in the rules of index construction. This change in diversity of the index has a material effect on cross-sectional dispersion and for this reason, data prior to January 1997 has been excluded. "The JSE Actuaries indices were replaced by the FTSE/JSE Africa Index Series on the 24th of June 2002. FTSE and the JSE provided historic data of the indices for the period July 1995 to December 2001 and the indicative values from the 2nd of January 2002 to the 21st of June 2002." http://ftse.jse.co.za/history_2002.jsp
}

In their study of developed market cross-sectional correlation, Ankrim and Ding (2002) suggested that one of the reasons for the increase in cross-sectional correlation that they had observed were that listings may be taking place earlier in the life cycle of companies. Presumably they were pointing to a greater diversity in listed equities as well as a lower concentration in the relative weighting of such equities. By way of comparison, Figure shows the number of stocks and the effective number of stocks ${ }^{10}$ on the FTSE JSE All Share Index since January 1997.

Table 1: Cross-sectional standard deviation on the J203 (FTSE JSE All Share Index)

\begin{tabular}{l|c|c}
\hline \multicolumn{3}{c}{ Weighted Cross-sectional Std Dev (1996 to 2009) } \\
\hline Max & $20,9 \%$ & $31-$ Oct-98 \\
\hline Median & $7,7 \%$ & \\
\hline Min & $4,1 \%$ & $31-J u l-04$ \\
\hline Inter Quartile Range & $4,0 \%$ & \\
\hline
\end{tabular}

The J203 has seen a marked decline in both the number of stocks and an increase in concentration from 1998 to 2001 and that could certainly have contributed to the declining cross-sectional opportunities evident in the early part of this century shown in Figure 1. However, after 2001 there doesn't seem to be any particular relationship between the concentration of the index and the variation in its stocks' performances. The All Share Index (free float adjustments considered) currently stands at approximately 20 effective stocks.

\section{Sectoral evidence}

While the cross-sectional diversity of the index is relevant to general equity managers and investors, specialised sector portfolios or portfolios which prefer to remain sector neutral will be concerned with the cross-sectional diversity of the sectors within the JSE All Share Index.

Figure 3 displays the weighted cross-sectional standard deviation over time of all three major sectors alongside that of the JSE All Share Index. Since all three sectors are subsets of the All Share Index and by definition, less diverse, it's not surprising that their cross-sectional dispersion is generally lower than the All Share Index itself and follows the same historic pattern.

Although the resource sector is by far the most concentrated of the three sectors (about $60 \%$ of it's weighting in three stocks), it is the financial sector which has historically usually offered the lowest cross-sectional opportunities for the active manager. If, as Sapra (2008) argues, the size of the cross-sectional standard deviation is an indication of the

\footnotetext{
${ }^{10}$ The effective number of stocks is defined as the equivalent number of stocks in the index if the index was equally weighted. Mathematically, the effective number of stocks is $\sum \frac{1}{w_{\mathrm{i}}^{2}}$ where $w_{i}$ are the weights of each of the index constituents (Strongin, Petsch \& Sharenow, 2000).
} 
extent of active management that's possible in each of these sectors, it is important to note the relatively low opportunities offered to an active financial sector portfolio manager as opposed to those of an industrial or resources portfolio manager and provides some support for the differences in the expected scale of active performance and active risk in these specialist sector portfolios across time.

\section{Implications of cross-sectional volatility and its changes for portfolio management and mandate setting}

In professional portfolio management, the fund sponsor and/or consultant and the portfolio manager are both concerned with active return generation but can inadvertently contaminate their common objective by failing to consider how their collective decision-making corresponds with the prevailing market conditions.

The consultant or sponsor's role is to determine the fund objectives using asset/liability concerns, levels of funding, legislative properties and risk appetite amongst other criteria. In this way the fund sponsor sets out the investment objectives and restrictions so that all parties are clear on the road ahead. In fact, in relatively new legislation $\left(\mathrm{PF} 130^{11}\right)$, the requirements for the investment policy statement are specifically spelled out in "Principle 8: The Investment Performance of Fund Assets". A substantial part of this process is a negotiation of performance expectations which, in an active management context, involves setting target active risk levels for the fund. For the most part, the consultant/sponsor's decisions in this regard are independent of the portfolio manager's investment view and largely independent of current market conditions.

The portfolio manager's role is to have an investment view i.e. to forecast active returns on securities and assets. The point of interaction between these two parties is when the investment mandate, with its fund objectives and risk controls, meets the portfolio manager's portfolio construction process: the mechanism whereby the investment view is translated into an actual investment. By way of portfolio construction, the investment view, developed in the laboratory of news, information, models, history and experience, is translated in the best possible way into an allocation of money across a variety of available assets. This allocation must meet with a variety of constraints: net individual investments that are not too short, too concentrated, too geared or traded too often while simultaneously aligning with particular styles and ensuring neutrality with others. This allocation must be achieved while maintaining a given level or band of active risk.

\section{Implications for mandate setting}

This section focuses particularly on the setting of active risk targets or expectations and its implications on active management in varying market conditions. Implementing an

\footnotetext{
${ }^{11}$ Draft circular PF 130: Good governance of retirement funds, available online at

http://www.irf.org.za/Documents/pdf\%20files/Legal\%20Technical/071 0\%20-\%20Draft\%20Governance\%20Circular\%20PF130.pdf.
}

investment view with a particular active risk in mind requires a sufficient "carrying capacity ${ }^{12}$ " for active risk which varies over time. "Carrying capacity" is a phrase borrowed from environmental science and indicates the number of individual organisms that can be sustained by an ecosystem without negatively impacting the organisms or their environment. As such, this ecological notion is an apt analogy for the cross-sectional dispersion of an investment environment at any given time: without sufficient crosssectional dispersion, high active weights cannot be achieved without leverage or substantial relaxation of the typical mandated portfolio constraints.

As a starting point, we rely on the work of Sapra (2008) and presume a so-called "unconstrained" portfolio management setting where the active manager is free to invest both long and short, in a way that optimally reflects their investment view in the portfolio. The active risk of such a portfolio is proportional to three particular parameters: a) the active weights, b) the cross-sectional risk of the investment universe and c) the size of the investment universe.

\section{Equation 6: Active risk components of an unconstrained portfolio}

$\sigma_{\mathrm{A}} \propto \mathrm{w}_{\mathrm{A}} \sigma_{\mathrm{cs}} \sqrt{\mathrm{N}}$

where

$\sigma_{\mathrm{A}}$ is the target active risk of the portfolio

$\mathrm{w}_{\mathrm{A}}$ is a vector of the active weights or active investment positions making up the portfolio and

$\mathrm{N}$ is the number of securities in the permitted investment environment.

Cross sectional risk and the size of the investment universe, are a function of market conditions and the mandated investment universe. The previous section showed these parameters (particularly the former) to be time-varying and, unfortunately, outside of the control of either the fund sponsor or the portfolio manager once the portfolio domain has been decided. The active weights of a portfolio is the domain of the portfolio manager and represents their decisions while the target active risk is the expression of the fund sponsor's objectives in terms of the portfolio's aggression.

\footnotetext{
${ }^{12}$ Yu and Sharaiha (2007) refers to this concept as "alpha granularity".
} 


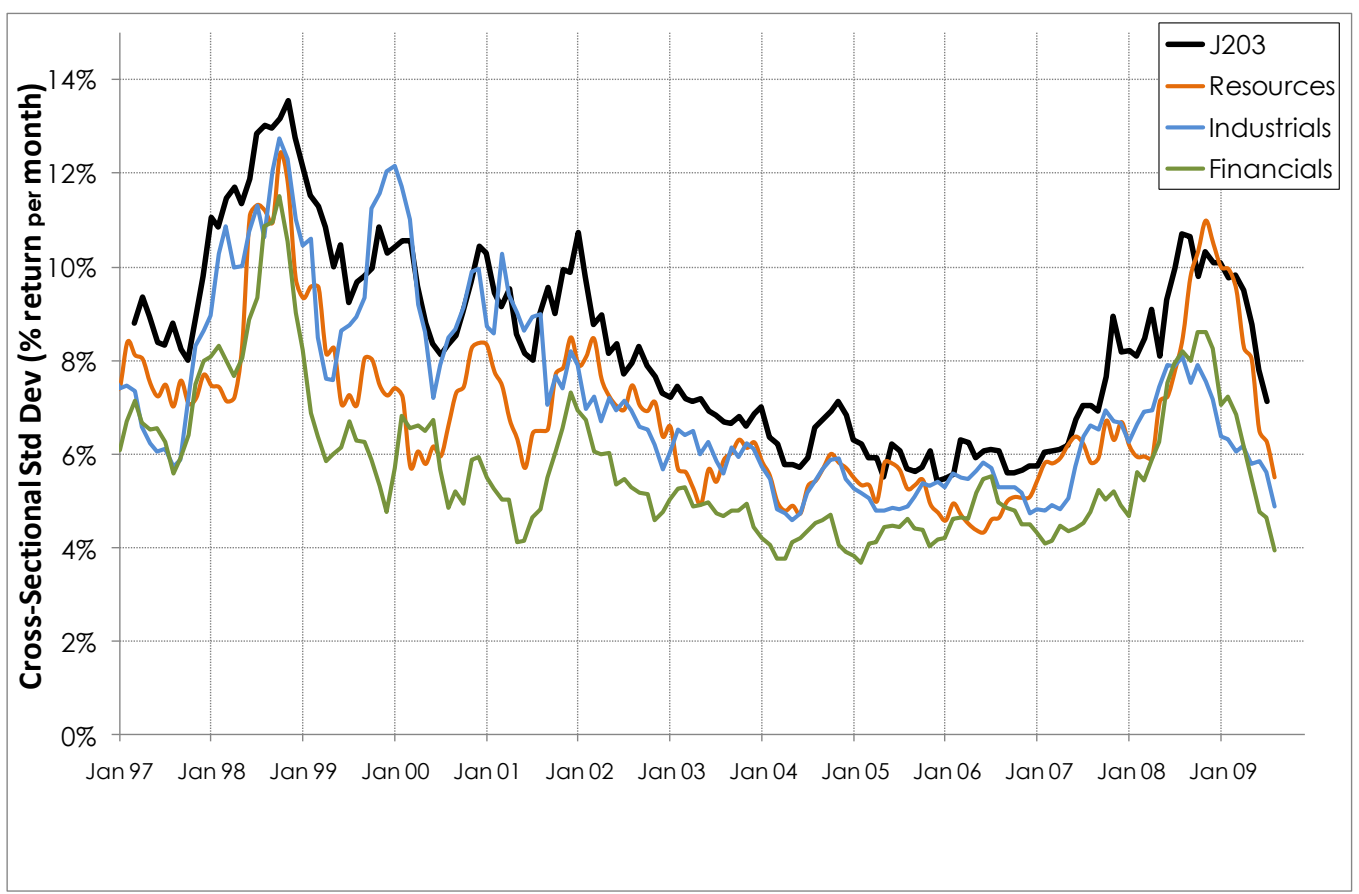

Figure 3: Cross-sectional standard deviation on the FTSE/JSE sectors over time

The relationship between the target active risk and the active weights are obvious. The more confident and aggressive the active manager in pursuing their investment view, the larger the active positions of the portfolio will be and consequently, the higher the active risk (all other things being equal). Much of the risk budgeting process and the active risk expectations are based on this simple principle. After all, the ultimate way in which a portfolio manager can express themselves is in their active positions. The fund sponsor would be wise to expect these to reflect both the view and the level of active risk on the part of the portfolio manager.

Equation 6 illustrates that the relationship between active risk and active weights must also involve the complex, multi-dimensional relationships between securities. In particular, in the simplified world of the unconstrained portfolio manager, the higher the cross-sectional volatility in the investment environment, the more easily an active portfolio manager can acquire the required active risk. Conversely, when the cross-sectional variation "dries up" the active manager must implement larger active weights to maintain the active risk target.

Good betting strategy would increase the stakes when the opportunities are high and vice versa. Following this directive, the rational, optimal and unconstrained active portfolio manager would take large active positions when the market has high cross-sectional dispersion and small active positions when the cross-sectional variation is low. Consequently, the active risk of their portfolio would wax and wane with increases and decreases in the dispersion among stocks.

In practice, a widely varying active risk would be a concern for fund sponsors who, typically, anchor the active risk for their portfolios to a particular range or level, independent of market conditions. Fund sponsors may, for example, wish to maintain a certain active risk level in a portfolio in order to fit their particular long-term risk budgets or funding levels. Similarly, active managers can set their sights on a particular active risk quantum with which they define their particular lack of benchmark-fear ${ }^{13}$ ! Accordingly the rational, optimal active portfolio manager, constrained to a rigid active risk, would behave contrary to good betting strategy when cross-sectional dispersion changes by increasing their active positions in their portfolios when opportunities are low and decreasing their bets when the market shows greater dispersion in security returns.

As shown in Figure 1, this capacity of the FTSE/JSE to deliver active risk-taking opportunities has been reducing steadily since the 1998 recovery to 2007. Given the relationship between cross-sectional volatility and active risk, portfolio managers and sponsors should have become accustomed to steadily decreasing active risk in their portfolios over that period. But if sponsors and managers required constant levels of active risk throughout this period, active managers would have become accustomed to increasing active weights and, for managers whose mandates allow the incurring of liabilities, increased gearing. According to Tobin's Separation Theorem (Tobin, 1958) and its application in an active management framework, if you can't achieve the same amount of active risk as you've learnt to expect historically in a low opportunity market, the most efficient solution is to gear up.

Khandani and Lo (2007) put forward the un-testable hypothesis that this kind of behaviour by hedge fund managers likely precipitated the hedge fund crisis of August 2007: cross-sectional volatility had been diminishing for years (as were the returns to over-crowded strategies) but clients and managers resisted allowing their active risk and return expectations to wane in response. Consequently, the

\footnotetext{
13"Benchmark-fear" is one of the hypotheses that Bernstein (1998) put forward as a possible explanation for the decline in fund performance dispersion before the 1990's.
} 
strategies remained the same but the gearing increased as the carrying capacity decreased, leaving many hedge funds in an irresponsibly vulnerable position when the credit crunch came.

Gearing and credit-risk are less of a concern in the realm of long-only portfolio management (typical of South African pension fund mandates). However, long-only managers are not immunised from the effects of decreasing cross-sectional volatility. The long-only active manager, like his/her unconstrained counterparts, can only maintain a constant active risk in a market with decreasing dispersion by increasing their active weights. However, the long only manager will, at some point, for some assets, meet the boundary of the negative active weights possible for securities that can only be held long. When all the opportunities to express their investment view without corruption have been used up, the long-only manager must increase active weights in areas where they can rather than where their investment view implies they should. Large fund size, a small and concentrated investment universe, and several additional mandated risk controls and limits exacerbate this distortion of the investment view.

In this way, when the decision makers set portfolio mandates and objectives with rigid, under-researched active risk targets and portfolio constraints, the translation of an investment view into a portfolio of investments becomes distorted with changes in the "carrying capacity" of their investment universe. In particular, when the cross-sectional variation in the market reduces, the resulting portfolio can be too active for the carrying capacity of its investment universe and, worse still, inconsistent with the manager's investment view. Furthermore, when the portfolio manager's performance is assessed, the ex post performance of the portfolio might bear little resemblance to the portfolio managers' intended source of active return. (The next section deals with some of the implications of the time varying nature of cross-sectional variation with regards to performance monitoring.)

Therefore, when setting the investment objectives of a fund, fund sponsors should be mindful of the tools at each decision maker's disposal as well as the conditions of the market at each point in time. Fund sponsors can set target active risk levels and portfolio managers can widen the active weights but, if these requirements and the portfolio's constraints aren't matched to the market's capacity to deliver active return (i.e. the cross-sectional dispersion on the market), the investment process can be considerably contaminated.

\section{Mandate compliance and forecast errors}

When fund sponsors monitor mandate compliance and whether their selected managers are delivering according to the sponsors' expectations, they will typically receive performance reports using forecast active risk and information ratios as indications of the positioning of the portfolio. Using an established and accepted risk model representing the investment universe (usually provided by an independent service provider and based for the most part on ex post stock behaviour), the ex ante active risk will be calculated by multiplying the current active positions in the portfolio (which are required to be mandate compliant) by the covariance matrix of forecast active returns (refer Equation 7).

\section{Equation 7: Ex-ante active risk estimation}

$\sigma_{\mathrm{a}}=\left(\mathrm{w}_{\mathrm{A}}{ }^{\prime} \Sigma \mathrm{w}_{\mathrm{A}}\right)^{\frac{1}{2}}$

where

$\sigma_{\mathrm{a}}$ is the ex-ante active risk forecast and

\section{$\Sigma$ is the covariance matrix of forecast active returns}

Many fund sponsors and active managers in South Africa were taken by surprise by a growing increase in their active risks over 2007 and continuing into 2008. In several cases, mandated risk levels were enforced and active portfolio positions were cut in order to bring portfolios back to compliant levels. The source of these dramatic increases in ex ante active risk forecasts lay in the steep increase in the JSE's cross-sectional risk from 2007 to 2008 evident in Figure 1. In the simplified expression of the relationship between realised active risk and forecast active risk, developed in Sapra (2008) (refer Equation 4), the forecast error in active risk is shown to be directly proportional to the forecast error in cross-sectional standard deviation. By implication then, if portfolio managers and sponsors are neglecting to monitor the changes in cross-sectional standard deviation by using long-term longitudinal risk models, the anticipated ex ante active risk can be surprisingly different to the realised active risk and insensitive to changes in the active management environment.

To illustrate the extent of this potential "shock" to active risk estimations, Figure 4 shows the ratio of the realised cross-sectional standard deviation to its one month lag. This provides an indication of the error multiple of forecast active risk from month to month (for fund sponsors who receive monthly performance reports).

The extent to which the realised active risk differed from the targeted active risk, implied by this relationship between realised and forecast cross-sectional standard deviation, varied between $40 \%$ to nearly double the active risk realised compared to the intended active risk of the portfolio. By implication, when using active risk as a measure of mandate compliance, the potential decision making consequences are severe. If the realised active risk is considered unexpectedly high, the portfolio manager could be required to cut positions which, under different market circumstances, would have been quite acceptable and vice versa.

Figure 2 illustrates the potential drift in the accuracy of the forecast active risk over a calendar year using increasing lags from each year-end in the ratio of realised crosssectional standard deviation. This illustration attempts to show, on a calendar year basis, the effect of changes in cross-sectional risk on the active risk statistic. 


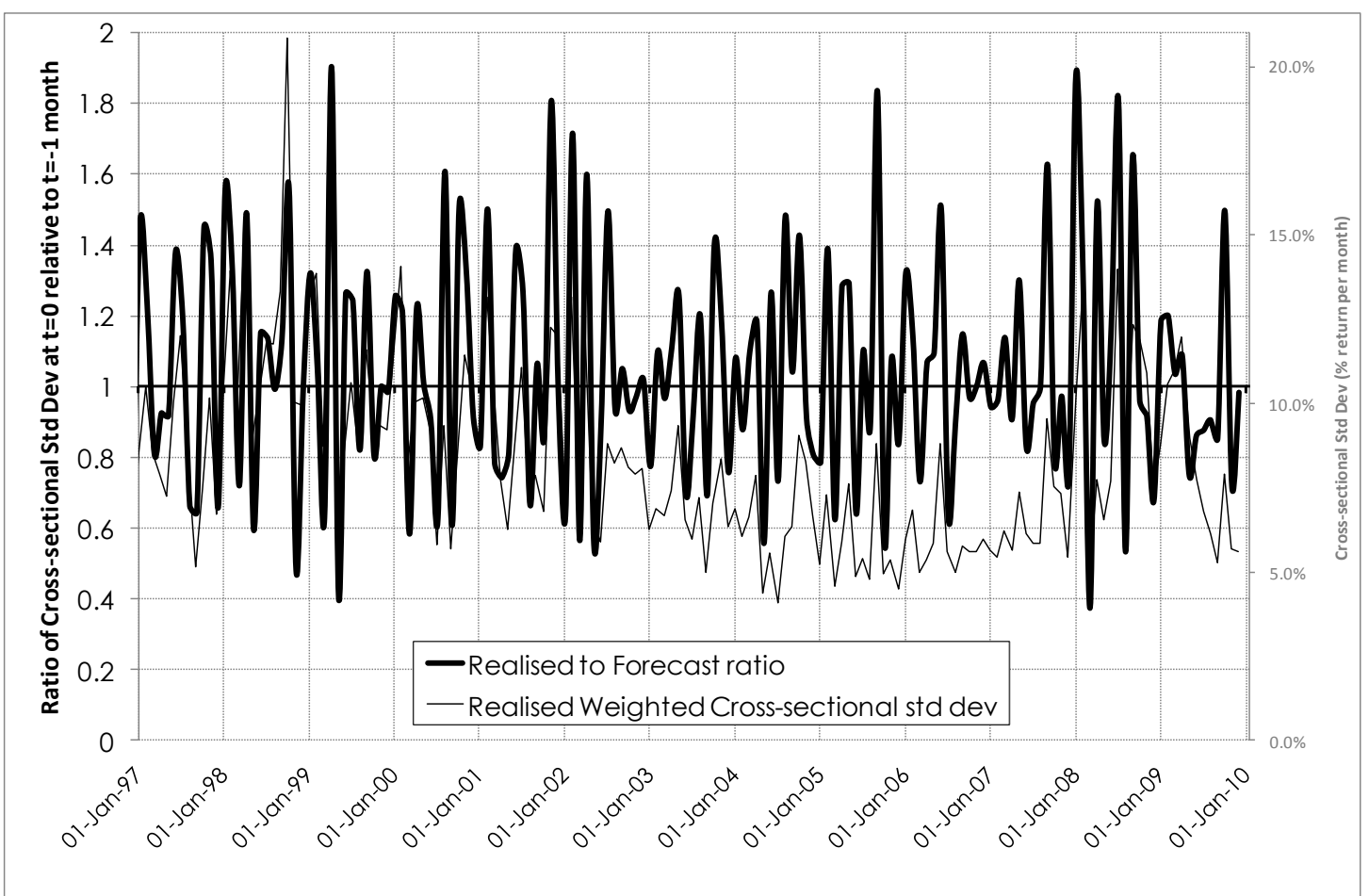

Figure 1: Ratio of realised cross-sectional standard deviation to its one month lag

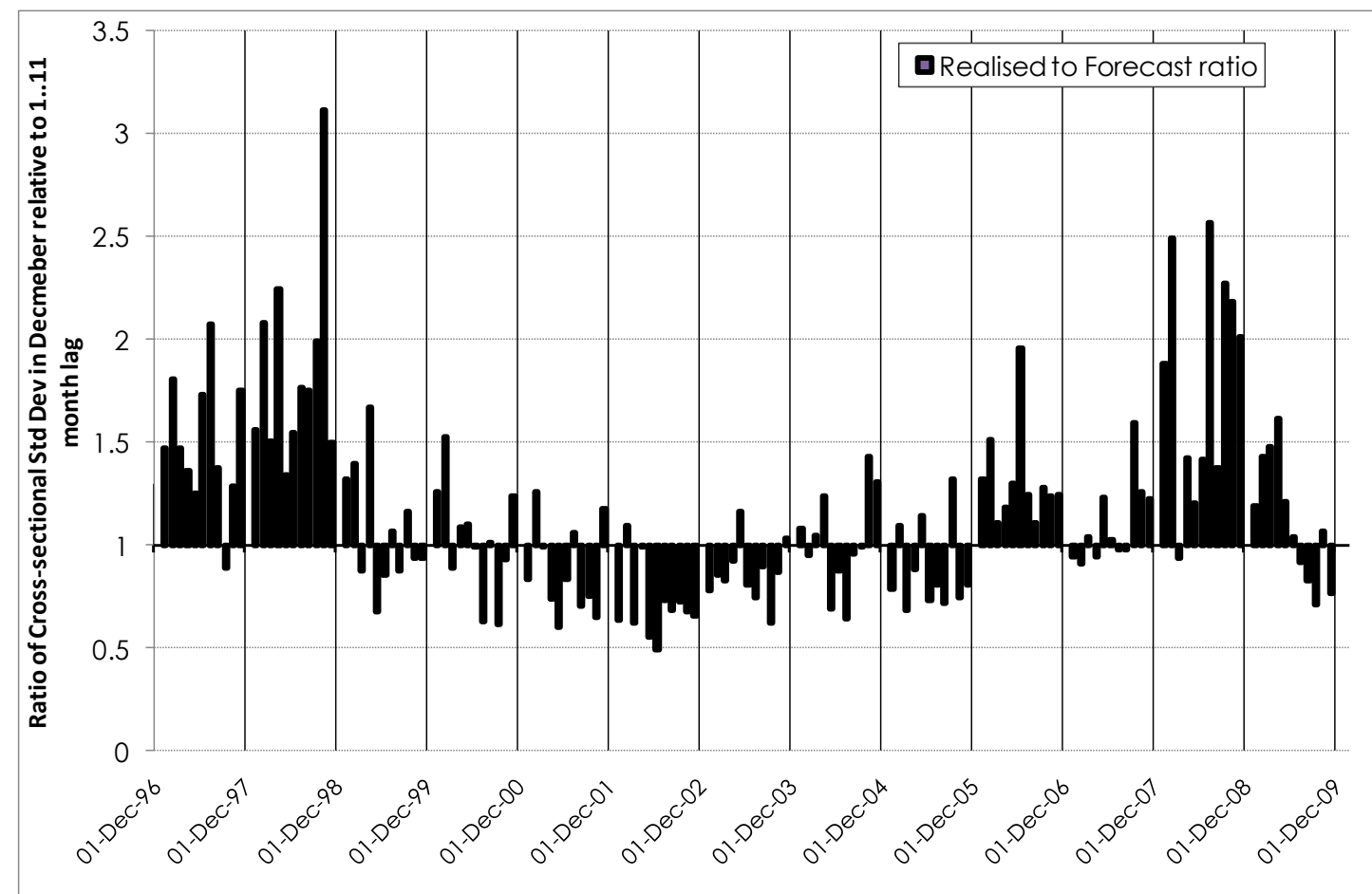

Figure 2: Realised cross-sectional standard deviation relative to increasing lags 
Figure 2 demonstrates the relative size of the shock to active risk that the year 2008 presented in our market. There were times within 2008 where the realised active risk would have been two and a half times the size implied by the January cross-sectional risk of the market, making asset managers appear to have radically increased their risk appetites when in fact the equity market was simply changing the spread in its investment offerings.

The implication of this relationship between cross-sectional market conditions and active risk forecasts is that sponsors should expect the active risk estimate of any portfolio to vary under varying market conditions. A change in an ex ante active risk could be an indication of changing active weights or portfolio aggression, which is why this monitoring is important. However, it is also very possible that changes in the ex-ante active risk of a portfolio is simply a reaction to changes in market conditions. Sponsors and their managers should therefore exercise caution when reacting to short term changes in this estimate on their performance reports by closing out active positions.

\section{Conclusions}

Cross-sectional volatility and its changes are a good measure of the investment opportunity set for active managers. The more dispersed the returns of investments are, the more opportunities there are for active managers to perform differently (preferably better!) from their competitors and the benchmark.

Cross-sectional volatility has changed substantially over time as have the opportunities for superior active performance and there is no reason to expect that the crosssectional risk of the market won't continue to vary over time. The relationship between this changing cross-sectional volatility and the dispersion of active portfolio managers further illustrates the importance of cross-sectional volatility to active management.

Ex ante, cross-sectional volatility must be considered handin-hand with risk limits and active risk targets when mandates are set or monitored. The higher the crosssectional volatility, the greater the opportunity for active risk taking, all other things being equal. Conversely, to remain efficient, active risk taking should be reduced during periods of low cross-sectional dispersion.

Furthermore, when fund sponsors monitor changes in an ex ante active risk they should bear in mind that changes in the active risk forecast of a portfolio could be a reaction to changes in market conditions and not the result of changes in the active positions of the fund. Sponsors and their managers should therefore exercise caution when reacting to changes in active risk estimates, mindful of the relationship between cross-sectional dispersion and active risk.

\section{References}

Ang, A., Hodrick, J. R., Xing Y. \& Zhang, X. 2006. 'The cross-section of volatility and expected returns', The Journal of Finance, 61 (1): 259 - 299.
Ankrim, E. M. \& Ding, Z. 2002. 'Cross-sectional volatility and return dispersion', Financial Analysts Journal, Sept/Oct:67 - 73 .

Bernstein, P. L. 1998. 'Where, oh where are the .400 hitters of yesteryear?', Financial Analysts Journal, 56(6):6 - 14.

Buckle, D. J. 2005. 'Ex post reality versus Ex ante theory of the fundamental law of active management', Journal of Asset Management, 6(1): 21 - 32.

Buckle, D. J. 2004. 'How to calculate breadth: An evolution of the fundamental law of active portfolio management', Journal of Asset Management, 4:54 - 63.

Clarke, R. G., De Silva, H., Sapra, S. \& Thorley, S. 2008. 'Long-short extensions: How much is enough?', Financial Analysts Journal, Jan/Feb: 16 - 30.

Clarke, R. G., De Silva, H. \& Thorley, S. 2010. 'Know your VMS exposure', Journal of Portfolio Management, Winter: $52-59$.

De Silva, H., Sapra, S. G. \& Thorley, S. 2001. 'Return dispersion and active management', Financial Analysts Journal, Sept/Oct: 29 - 42.

Gorman, L. R; Sapra, S. G. \& Weigand, R. A. 2009. 'The role of cross-sectional dispersion in active portfolio management'. Working paper, [online] URL:http://papers.ssrn.com/sol3/papers.cfm?abstract_id=14 44868 .

Grinold, R. C. 1989. 'The fundamental law of active management', Journal of Portfolio Management, Spring: 30 -37 .

Grinold, R. C. 1994. 'Alpha is volatility times IC times score. Real Alphas don't get eaten', Journal of Portfolio Management, Summer: 9 - 16.

Khandani, A. E. \& Lo, A. W. 2007. 'What happened to the Quants in August 2007?' [online] URL:http://ssrn.com/abstract=1015987.

Kritzman, M. P. 2003. The portable financial analyst: What practitioners need to know. New Jersey: John Wiley and Sons Inc.

Kritzman, M. 1998. Wrong and alone. Economics \& portfolio strategy. New York: Peter L. Bernstein, Inc.

Markowitz, H. M. 1952. 'Portfolio selection', The Journal of Finance, 7: 77 - 91.

Ratner, M., Meric, I. \& Meric, G. 2006. 'Sector dispersion and stock market predictability', Journal of Investing, 15(1): $56-61$.

Raubenheimer, H. 2010. 'Concentration in the South African equity market and its implied restrictions on the long only equity fund manager's opportunity set', South African Journal of Business Management, 41(4):1-10. 
Raubenheimer, H. \& Conradie, H. 2009. 'Be careful what you wish for - Active risk is market dependent', Collective Insight, Autumn, FinWeek, pp.17-19.

Sapra, S. G. 2008. 'The role of cross-sectional dispersion in active portfolio management'. Working paper. [online] URL:ssrn.com/abstract=1266225, September.

Sharpe, W. F. 1991. 'The arithmetic of active management', Financial Analysts Journal, 47(1): 7 - 9.

Solnik, B. \& Roulet, J. 2000. 'Dispersion as cross-sectional correlation', Financial Analysts Journal, 56(1):54 - 61.

Sorensen, E., Hua, R. \& Qian, E. 2006. 'Aspects of constrained long-short equity portfolios', Journal of Portfolio Management, 33(2):12 - 22.

Strongin, S., Petsch, M. \& Sharenow, G. 2000. 'Beating benchmarks', Journal of Portfolio Management, 26(4):11 27.

Tobin, J. 1958. 'Liquidity preference as behavior towards risk', The Review of Economic Studies, 67: 65 - 86.

Ye, J. 2008. 'How variation in signal quality affects performance', Financial Analysts Journal, 64(4):48 - 61.

Yu, W. \& Sharaiha, Y. M. 2007. 'Alpha budgeting - Crosssectional dispersion decomposed', Journal of Asset Management, 8(1):58 - 72.

Zhou, G. 2008. 'On the fundamental law of active portfolio management: What happens if our estimates are wrong?', The Journal of Portfolio Management, Summer:26 - 33. 